\title{
Nonparametric estimation of characteristics of the interspike interval distribution
}

\author{
Ondrej Pokora ${ }^{1 *}$, Lubomir Kostal $^{2}$ \\ From 24th Annual Computational Neuroscience Meeting: CNS*2015 \\ Prague, Czech Republic. 18-23 July 2015
}

We address the problem of non-parametric estimation of the probability density function as a description of the probability distribution of noncorrelated interspike intervals (ISI) in records of neuronal activity. We also continue our previous effort $[1,2]$ to propose alternative estimators of the variability measures. Kernel density estimators are probably the most frequently used non-parametric estimators of the probability distribution. However, there are also other non-parametric approaches. We focus on non-parametric methods based on a principle of extrema of the Fisher information. Specifically, we focus on the maximum penalized likelihood estimation of the probability density function proposed by Good and Gaskins [3], which can be understood as a kernel estimator with a particular kernel function [4]. Other non-parametric approach we would like to address is the spline interpolation proposed by Huber [5] which can uniquely estimate the ISI distribution.
4. Eggermont PPB, LaRiccia VN: Maximum Penalized Likelihood Estimation: Volume I: Density Estimation. Springer 2001.

5. Huber PJ: Fisher information and spline interpolation. Ann. Stat 1974, 2:1029-1033.

doi:10.1186/1471-2202-16-S1-P131

Cite this article as: Pokora and Kostal: Nonparametric estimation of characteristics of the interspike interval distribution. BMC Neuroscience 2015 16(Suppl 1):P131.

\section{Acknowledgements \\ This work was supported by the Czech Science Foundation (GACR) grants \\ 15-06991S (Ondrej Pokora) and 15-08066S (Lubomir Kostal).}

\section{Authors' details}

'Department of Mathematics and Statistics, Faculty of Science, Masaryk

University, Brno, Czech Republic. ${ }^{2}$ Institute of Physiology, Academy of

Sciences of the Czech Republic, Prague, Czech Republic.

Published: 18 December 2015

\section{References}

1. Kostal L, Lansky P, Pokora O: Variability measures of positive random variables. PLOS ONE 2011, 6:e21998.

2. Kostal L, Pokora O: Nonparametric Estimation of Information-Based Measures of Statistical Dispersion. Entropy 2012, 14:1221-1233.

3. Good IJ, Gaskins RA: Nonparametric roughness penalties for probability densities. Biometrika 1971, 58:255-277.

\footnotetext{
* Correspondence: pokora@math.muni.cz

'Department of Mathematics and Statistics, Faculty of Science, Masaryk University, Brno, Czech Republic

Full list of author information is available at the end of the article
}

Submit your next manuscript to BioMed Central and take full advantage of:

- Convenient online submission

- Thorough peer review

- No space constraints or color figure charges

- Immediate publication on acceptance

- Inclusion in PubMed, CAS, Scopus and Google Scholar

- Research which is freely available for redistribution

Submit your manuscript at www.biomedcentral.com/submit
() Biomed Central 